\title{
Stepwise Disinfestation Reduces Contamination of Huperzia lucidula Shoot-tips and Gemmae
}

\author{
Alice Spurlin Waegel ${ }^{1}$ \\ Division of Arts and Sciences, Neumann College, Aston, PA 19014 \\ Additional index words. shining club moss, in vitro culture, contamination, surface
sterilization
}

\begin{abstract}
Shining club moss, Huperzia lucidula (Michaux) Trevisan, can be propagated in tissue culture, but it is difficult to obtain sterile explants. When standard disinfestation methods were used, $100 \%$ of $\mathrm{H}$. lucidula apical shoot-tips disinfested for 10,20 , or 30 minutes with $1 \%$ sodium hypochlorite/ $0.15 \%$ Tween 20 became contaminated or browned within 3 weeks. Since this club moss is highly contaminated, a stepwise disinfestation procedure was developed to eradicate spore forming microbes. Based on the principle that vegetative microbial cells are more easily destroyed than spores, stepwise disinfestation induced spore germination before explant treatment with sodium hypochlorite. A 48-hour disinfestation treatment resulted in $\mathbf{5 0 \%}$ explant survival without visible contamination. Fewer explants (22\%) were successfully disinfested when a 24-hour stepwise disinfestation was used. Applying the stepwise disinfestation method to contaminated cultures after a standard disinfestation protocol produced an additional 15.6\% contamination-free club moss shoot-tips. After successful surface disinfestation, $\boldsymbol{H}$. lucidula shoot-tips and gemmae established in vitro grew normally.
\end{abstract}

Shining club moss, Huperzia lucidula (Michaux) Trevisan, is an attractive northeastern United States native that deserves better representation in today's gardens. Efforts have been made to propagate this plant since the 1700s (Barrows, 1935), but these efforts have been fraught with difficulties. Growing H. lucidula from spores is not practical since the germination rates are low and growth is slow, regardless of the growing medium, light, temperature, and alcohol treatments (Barrows, 1935). Only $0.3 \%$ of Huperzia lucidula spores germinated in vitro after 9 months, with none producing mature gametophytes in culture (Whittier, 1986, 1998). Based on this information, mass production of shining club mosses from spores appears extremely unlikely.

Although cultivating shining club moss from spores has met with little success, growing sporophyte cuttings and gemmae has been more productive (Barrows, 1935). Cuttings root readily in a mixture of peat and sand under greenhouse conditions so they may also grow in tissue culture. One difficulty with culturing $H$. lucidula is obtaining sterile explants. Shining club moss grows close to the ground and has subterranean gametophytes associated with mycorrhizal fungi, so explants tend to be highly contaminated with soil microbes, including spore forming bacteria and fungi. Since standard chemical disinfestation methods using sodium hypochlorite (bleach)

Received for publication 11 Mar. 2002. Accepted for publication 17 Sept. 2002. This study was made possible with the assistance of Sherry Kitto, who provided facilities, instruction, and encouragement during my sabbatical leave at the Plant and Soil Sciences Dept., College of Agriculture, Univ. of Delaware. ${ }^{1}$ Professor. are relatively ineffective against spores, surface sterilizing club moss explants can be difficult.

To overcome the spore problem, a stepwise disinfestation procedure was developed for decontaminating Huperzia lucidula shoot- tip cuttings and gemmae prior to culture. This new decontamination process was based on a method to sterilize heat labile culture media, described as fractional sterilization (tyndallization) by the 19th century British scientist John Tyndall. Stepwise disinfestation, like tyndallization, operates on the principle that vegetative microbial cells are more easily killed than spores. However, stepwise disinfestation uses sodium hypochlorite solutions to kill vegetative microbes, whereas tyndallization uses heat. In both processes, a bactericidal treatment (heat or bleach) is followed by an incubation period under conditions favorable for the germination of microbial spores. After incubation, the bactericidal treatment is repeated to kill newly produced vegetative cells, followed by another incubation and a third bactericidal treatment - the intent being that all fungal spores and bacterial endospores will have germinated and the resulting vegetative cells killed.

\section{Materials and Methods}

Explants. Huperzia lucidula shoot-tip cuttings and gemmae were collected from woodlands in southeastern Pennsylvania and northwestern Delaware in Sept. 2000 (144 shoot-tips), Oct. 2000 (28 shoot-tips and 8 gemmae), and Aug. 2001 (30 gemmae). Explants were transported and maintained at $4{ }^{\circ} \mathrm{C}$ for $1-2 \mathrm{~d}$ until disinfested and cultured. A typical specimen is shown in Fig. 1A.

Culture medium. Club moss liquid me- dium contained (per liter): $50 \mathrm{mg} \mathrm{MgSO}_{4} \cdot 7$ $\mathrm{H}_{2} \mathrm{O} ; 26.5 \mathrm{mg} \mathrm{CaCl}{ }_{2} \cdot 2 \mathrm{H}_{2} \mathrm{O} ; 50 \mathrm{mg} \mathrm{K}_{2} \mathrm{PO}_{4} ; 50$ $\mathrm{mg} \mathrm{NH} \mathrm{N}_{4} \mathrm{Cl} ; 2 \mathrm{~g}$ dextrose; and half-strength Murashige and Skoog (1962) basal salts micronutrients. Semi-solid medium contained $0.8 \%$ Phytagar (Gibco , Invitrogen, Carlsbad, Calif.) as a gelling agent. The $\mathrm{pH}$ was adjusted to 5.1-5.3 before autoclaving (Whittier, 1986, 1998).

Standard disinfestation. Three lots of 48 shoot-tip cuttings were washed in $250 \mathrm{~mL}$ tap water with one drop of detergent (Lemon Joy, Proctor and Gamble, Cincinatti) for $1 \mathrm{~min}$; then explants were immersed in $70 \%$ ethanol for 30 $\mathrm{s}$ with agitation. Individual explants in $25-\mathrm{mm}$ $\times 100-\mathrm{mm}$ tubes were then treated with $1 \% \mathrm{w} / \mathrm{v}$ sodium hypochlorite/ $0.15 \%$ Tween 20 solution for either $10 \mathrm{~min}(\operatorname{lot} \mathrm{A}), 20 \mathrm{~min}(\operatorname{lot} \mathrm{B})$, or 30 $\min (\operatorname{lot} \mathrm{C})$. Cuttings were then washed once with $10 \mathrm{~mL}$ sterile distilled water, trimmed to remove bleach damaged areas on stem bases and cultured on semisolid medium.

Repeat disinfestation: All cuttings (144) undergoing standard disinfestation eventually became contaminated and received a repeat disinfestation with $1 \% \mathrm{w} / \mathrm{v}$ sodium hypochorite $/ 0.15 \%$ Tween 20 for $20 \mathrm{~min}$, rinsed as above. When contamination persisted after several additional treatments, affected explants were either stepwise disinfested or discarded as the explant size diminished following trimming of damaged stems.

Stepwise disinfestation. Explants were washed in tap water with one drop of detergent for $1 \mathrm{~min}$, immersed in $70 \%$ ethanol for $30 \mathrm{~s}$ with agitation, then treated with $1 \%$ sodium hypochlorite $10.15 \%$ Tween 20 for $20 \mathrm{~min}$. Single explants were removed from the bleach and rinsed in individual $25-\times 100-\mathrm{mm}$ tubes containing $10 \mathrm{~mL}$ sterile distilled water for 10 min on a shaker (160 rpm). After rinsing, each explant was placed in a culture tube containing $10 \mathrm{~mL}$ of liquid medium and incubated on the shaker (under cool-white fluorescent lights, $50 \mu \mathrm{mol} \cdot \mathrm{m}^{-2} \cdot \mathrm{s}^{-1}, 16 \mathrm{~h}$-photoperiod) at room temperature for $24 \mathrm{~h}$.

At the end of the 24-h incubation period, $10 \mathrm{~mL}$ of $2 \%$ sodium hypochlorite $/ 0.3 \%$ Tween 20 (double strength) was added to each culture tube, mixed with the equal volume of medium in the tube and shaken for $20 \mathrm{~min}$. Individual explants were removed and placed in tubes with $10 \mathrm{~mL}$ sterile distilled water for a 10 min rinse with agitation. In the 24-h stepwise disinfestation procedure, club moss explants were trimmed after rinsing to remove bleach damaged basal ends, and cultured on club moss agar. In a 48-h stepwise disinfestation procedure, club moss explants were incubated in club moss broth (after rinsing) for a second 24-h period and treated again with double strength sodium hypochlorite solution for 20 min before rinsing, trimming and culturing on semi-solid medium.

After culture, explants were inspected daily for evidence of microbial growth, using a stereoscopic microscope. Contaminated cultures were subjected to additional stepwise disinfestation or discarded.

Statistical analysis. Club moss explants (n $=18$ for each group) were treated with either 


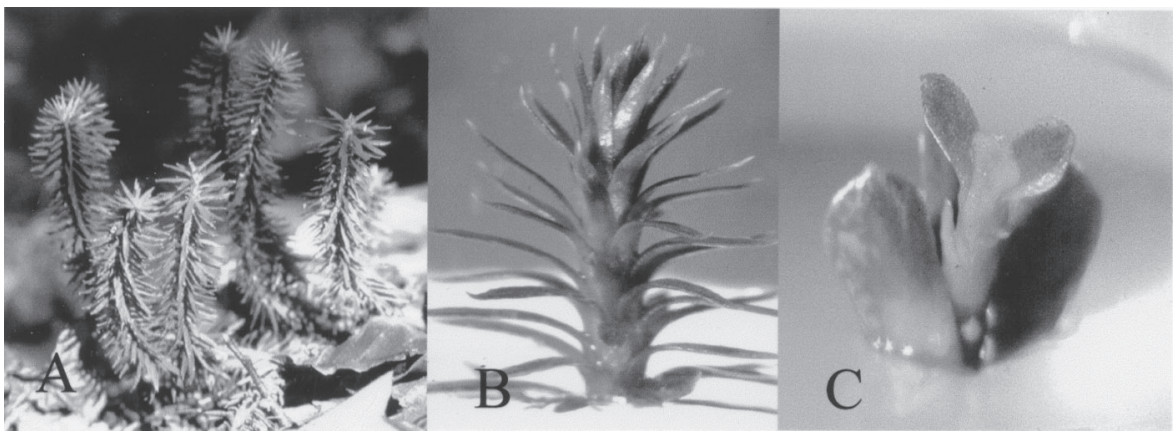

Fig.1. (A) Huperzia lucidula in its native habitat. Shoots $14-20 \mathrm{~cm}$. (B) Shoot-tip in culture 5 weeks after initiation, height $32 \mathrm{~mm}$. (C) Gemma producing shoot in vitro 5 weeks after initiation, height $6 \mathrm{~mm}$. a 20-min standard disinfestation (control), a 24-h stepwise disinfestation or a 48-h stepwise disinfestation. All explants were monitored for visible contamination for $38 \mathrm{~d}$. The percentage of contaminated cultures over time was calculated for each group and the Student's $t$ test (1 tailed) was used to determine the mean test difference between the control group and each stepwise disinfestation group.

\section{Results}

Standard disinfestation: All 144 Huperzia lucidula shoot-tips and gemmae disinfested for 10,20 , or 30 min with $1 \%$ sodium hypochlorite either became contaminated within 3 weeks or turned brown (3/144 explants turned brown and were discarded; one from the 20-min disinfestation protocol and two from the 30min disinfestation protocol). Although longer exposure to sodium hypochlorite slowed the appearance of visible microbial contamination, all cultures became contaminated within 3 weeks when standard disinfestation was used (Fig. 2).

Stepwise disinfestation: Stepwise disinfestation was performed on Huperzia lucidula explants ( 28 shoot-tips and 8 gemmae), which were then observed for contamination for $38 \mathrm{~d}$. The 48-h stepwise disinfestation reduced visible contamination ( $50 \%$ contamination free) better than the 24-h treatment (22\%) through 38 d (Fig. 3). After a 48-h stepwise disinfestation of 30 gemmae collected in Aug. 2001, $50 \%$ remained free of visible contamination for 6 months.

Both 24- and 48-h stepwise disinfestation results were significantly different from 20 min standard disinfestation results with the Student's $t$ test $(P \leq 0.01$ for $24 \mathrm{~h}$ vs. $20 \mathrm{~min}$ standard disinfestation; $P \leq 0.001$ for $48 \mathrm{~h}$ vs. 20 min standard disfestation ). However, results from the 24- and 48-h stepwise disinfestations were not significantly different from each other $(P=0.09)$.

Repeat disinfestation. After the failure of standard disinfestation procedures, contaminated club moss shoot-tips were treated again with sodium hypochlorite. After one repeat disinfestation, 13 explants $(9.2 \%)$ remained free of visible contamination and an additional 14 explants $(9.9 \%)$ were recovered after two to three disinfestation treatments. However, repeated standard disinfestations left most explants $(81 \%)$ contaminated, but an additional 22 of these club moss cultures $(15.6 \%)$ were subsequently cleaned by stepwise disinfestation. Since repeated exposures to sodium hypochlorite during stepwise or standard disinfestations damaged the explant, the damaged area was excised, decreasing the size of an shoot-tip. Eventually 92 (65\%) of the origi-

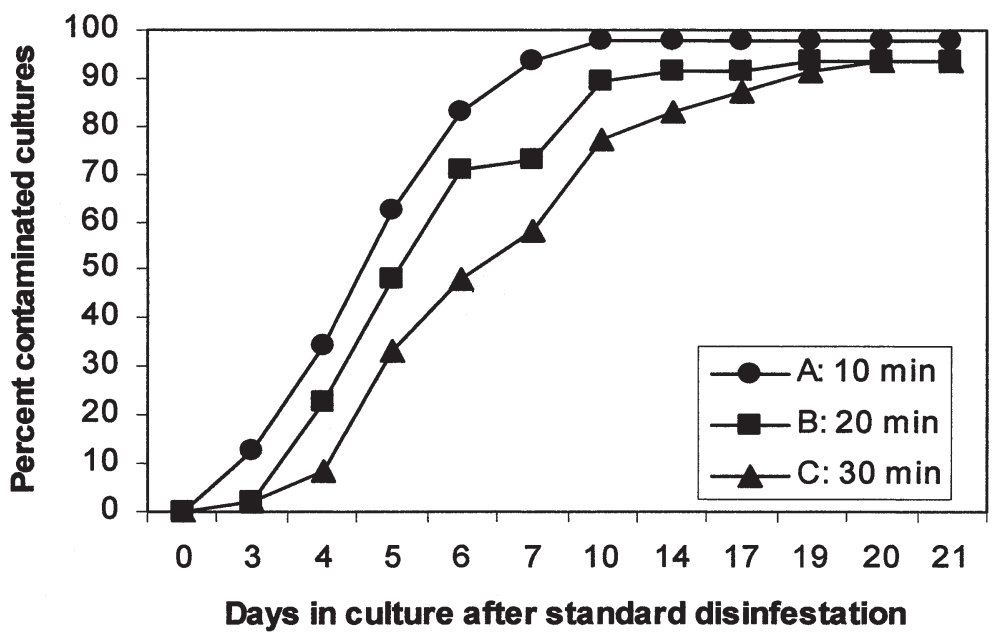

Fig. 2. Standard disinfestation-frequency of visibly contaminated club moss explants after disinfestation in $1.0 \%$ sodium hypochlorite for 10,20 , or $30 \mathrm{~min}(\mathrm{n}=48$ per treatment). nal explants were discarded due to refractory contamination and diminished size.

Besides reducing explant size, repeated exposure to sodium hypochlorite caused pale stripes to appear on the microphylls of $\mathrm{H}$. lucidula cuttings. This "zebra phenomenon" did not persist; in the absence of further exposure to sodium hypochlorite, green color returned to the explant after a few weeks in culture.

Green H. lucidula shoot-tips free of visible contamination (Fig. 1B) began to grow in vitro after 5 weeks. First the apex would broaden, increasing in width from $\approx 2 \mathrm{~mm}$ to $4 \mathrm{~mm}$ in diameter. Next, shoot-tips split and branched dichotomously in the typical Lycopodium pattern. Cultured H. lucidula gemmae grew differently than apices, but within the same time frame. After 5 weeks in axenic culture, gemmae produced small shoots with more rounded microphylls than a mature sporophyte (Fig 1C). After the shoot emerged and obtained a height of several millimeters, one to two roots developed from the proximal root primordium of the gemmae and penetrated 3-4 $\mathrm{mm}$ into the culture medium. Unlike Gillen and Basile (1986), who reported abnormal growth of gemmae in culture, the gemmae in this study produced small but complete plants, even in a simple nutrient medium without growth regulators.

\section{Discussion}

Surface disinfesting club moss explants with standard procedures was ineffective, with all cultures becoming contaminated within 3 weeks. The length of time required for microbial contamination to become evident (over $19 \mathrm{~d}$ in some cases) suggested that dormant fungal spores and bacterial endospores slowly germinated during exposure to the moist in vitro environment, so a stepwise disinfestation method was developed for club moss shoot-tips and gemmae. Unlike other non-standard methods for controlling microbial growth in plant tissue culture, such as eliminating sugars from the culture medium (Kozai et al., 1997), treating cultures with antibiotics (Falkiner, 1997), subjecting explants to hot water (Langens-Gerrits et al., 1998), or acidifying culture media (Leifert et al., 1994), stepwise disinfestation is specifically designed to eliminate fungi and bacteria after first encouraging latent spores to germinate.

Stepwise disinfestation was superior to standard methods for cleaning $H$. lucidula explants. The 48-h stepwise disinfestation procedure resulted in $50 \%$ more clean, viable explants than standard disinfestation. Refinements of this basic method may increase the percentage of clean plant material. One possible refinement, incubation of the plant material in liquid media at $30^{\circ} \mathrm{C}$ instead of room temperature, would facilitate the rapid germination of microbial spores. Another possibility is using three cycles of incubation and disinfestation instead of two to maximize spore germination and destruction. A third possibility would be to use different chemical disinfectants after each incubation such as sterile ethanol, hydrogen peroxide, benzylalkonium chloride, or iodine. 


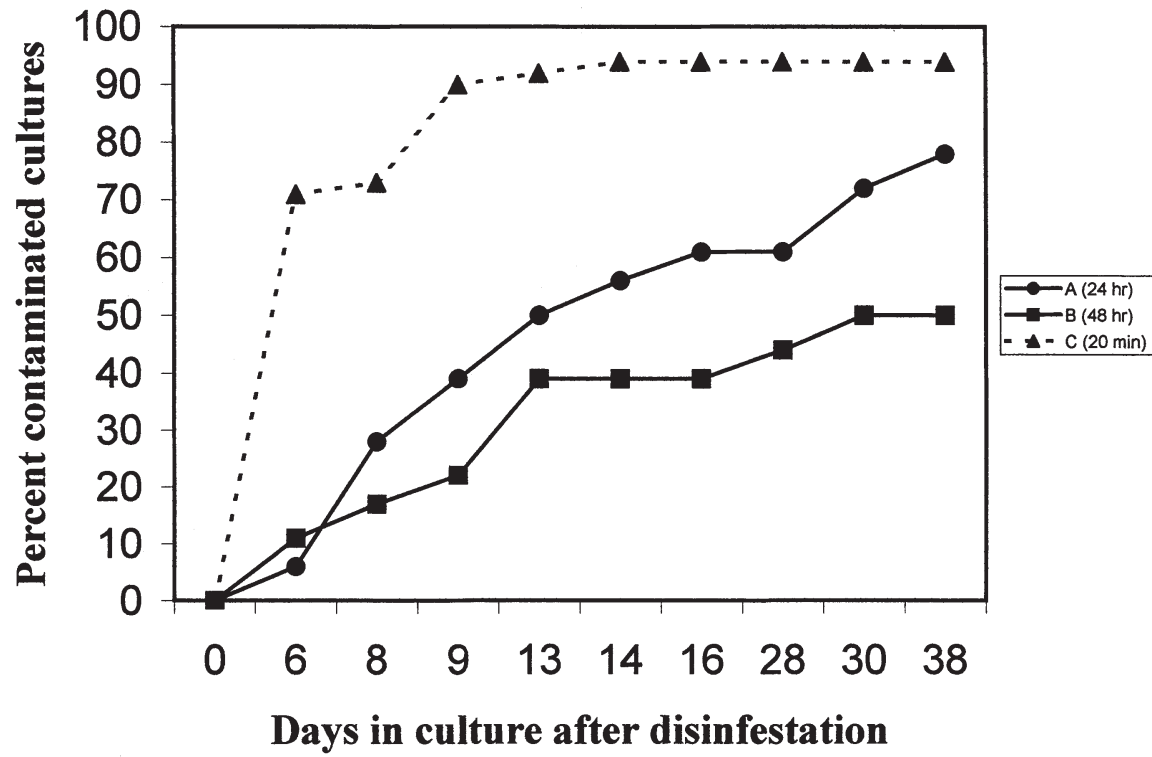

Fig. 3. (A) Frequency of contaminated club moss explants over $38 \mathrm{~d}$ after a 24-h stepwise disnfestation, (B) a 48-h stepwise disinfestation, or (C) a 20-min standard disinfestation control ( $\mathrm{n}=18$ per treatment). Stepwise disinfestation groups are significantly different from the control $(P \leq 0.01$ for $24-\mathrm{h}$ stepwise disinfestations and $P \leq 0.001$ for 48 -h stepwise disinfestations).

Microbes are less likely to develop genetic resistance to antimicrobial agents if subjected to a varied array. Even without the potential improvements in the stepwise disinfestation process, it should be applicable to a wide va- riety of plant material, especially for those in close contact with soil. The establishment of effective disinfestation protocols for Huperzia lucidula was necessary for future tissue culture experimentation with this species.

\section{Literature Cited}

Barrows, F.L. 1935. Propagation of Lycopodium. I. Spores, cuttings, and bulbils. Contrib. from Boyce Thompson Inst. 7:267-294.

Falkiner, F.R. 1997. Antibiotics in plant tissue culture and micropropagation - What are we aiming at? p. 155-160. In: A.C. Cassells (ed.). Pathogen and microbial contamination management in micropropagation. Kluwer Acad., Dordrecht, The Netherlands.

Gillen, J.J. and D.V. Basile. 1986. The growth of gemmae of Huperzialucidula (Lycopodiaceae) in axenic culture. Am. J. Bot. 73:736. (abstr.).

Kozai, T., C. Kubota, R. Jeong-Byoung, and B.R. Jeong.1997. Environmental control for the largescale production of plants through in vitro techniques. Plant Cell Tiss. Org. Cult. 51:49-56.

Langens-Gerrits, M., M. Alberts, and G.J.D. Klerk. 1998. Hot-water treatment before tissue culture reduces initial contamination in Lilium and Acer. Plant Cell Tiss. Org. Cult. 52:75-77.

Leifert, C., B. Waites, J.W. Keetley, S.M. Wright, J.R. Nicholas, and W.M. Waites. 1994. Effect of medium acidification on filamentous fungi, yeasts and bacterial contaminants in Delphinium tissue cultures. Plant Cell Tiss. Org. Cult. 36: 149-155.

Murashige, T. and F. Skoog. 1962. A revised medium for rapid growth and bio-assays with tobacco tissue cultures. Physiol. Plant. 15:473-497.

Whittier, D.P. 1986. Gametophytes of Lycopodium lucidulum from axenic culture. Amer. Fern J. 76:48-55.

Whittier, D.P. 1998. Germination of spores of the Lycopodiaceae in axenic culture. Amer. Fern J. 88:106-113. 